justified that when sodium compounds are used for 'modifying,' the protector is necessarily metallic sodium. As a result of this action, the formation of the normal eutectic is inhibited, and aluminium continues to be precipitated from the metal until the super-solubility line is reached.

It is also shown that the protection of the modified structure can be obtained without the use of the ordinary reagents provided that the rate of cooling is sufficiently rapid.

From the theory that certain substances hinder the aggregation of the colloid particles, it should be possible to discover also other substances capable of accelerating this aggregation. The compound $\mathrm{FeAl}_{3}$ is such a substance, and it has been experimentally substantiated that the presence of iron in melts of these silicon-aluminium alloys is detrimental.

A diagram has been drawn up for the 'modified' alloys indicating the manner in which under-cooling alters the normal process of solidification. The amount of the substances added to effect the "modi- fication' has been considered, and with sodium hydroxide, and for an alloy of about I2 per cent. of silicon, it is put at about 5 per cent. of the weight of the metal. Excess results in a deterioration of the mechanical properties.

The time which is allowed to elapse between the addition of the castings is also of importance, and, for the usual composition of alloy, should be about half an hour.

Since the general theory propounded is independent of any special constituent, it should be sufficiently general to apply to systems other than that imme. diately under consideration. This is shown to be the case, and exactly analogous results have been obtained in the systems copper-aluminium, aluminiumnickel, aluminium-manganese, lead-antimony, and copper-antimony.

The importance of the colloidal state in alloys at the moment of solidification, and of under-cooling, is thus shown to be far greater than has hitherto been generally appreciated.
F. C. T.

\title{
The Twelfth International Physiological Congress in Stockholm.
}

$\mathrm{F}$ ACH international congress, as a rule, discloses some special interest in one or another field of physiclogical science, as well as serving as a sure guide to the virility of the science in general. Contrasted with the last congress, held three years ago in Edinburgh, the present congress had no one central interest comparable to that excited by the isolation of insulin, but the fine attendance of the foremost representatives, with a considerable number of the younger workers, from all the continental European countries, was a welcome evidence of the general recovery of physiology from the devastating effects of the War, and of the steady and persistent advance in almost every branch of this science.

The congress in Stockholm was as beautifully arranged as in Edinburgh, and as regards the welcome and hospitality offered there is no need to say more than that it could not have been bettered. The scientific programme of the congress opened with an address by Sir Frederick Gowland Hopkins on "The Mechanisms of Biological Oxidations," in which he outlined the position attained by workers in this field, with especial reference to the work done in his own laboratory at Cambridge.

The routine work of the congress was divided into four sections which were grouped according to subjects, facilitating the attendance by each member at the discussions on those papers in which he was particularly interested.

Great interest was aroused by a number of papers dealing with the fundamental processes of life, as, for example, the communications of the recent important researches of Adrian upon the afferent impulses conducted by the single nerve fibre, and of Hill and Downing upon the measurement of heat production in nerve. An interesting summary was given by Kato (Tokyo) of his theory of decrementless conduction in the narcotised region of nerve, in which, as is well known, he is opposed to the findings of Keith Lucas and Adrian. The problem was the subject of a lively debate, and is probably now near to solution. Muscle physiology was represented by Embden, by Hill, and by Meyerhof.

Another point of great interest was the question with regard to tissue metabolism, mainly represented by Dale's school, in relation to insulin and to such problems as the development of rigor.

In the realm of the central nervous system, an interesting communication was made by Samojloff
(Kasan) upon the nature of spinal inhibition. His experiments tend to support the theory of a liberation of some chemical substance affecting the synopses or the cellular structures in the spinal cord. Magnus (Utrecht) made a further contribution to the subject of local and segmental reflexes in the decerebrated animal.

Metabolism was represented by Lusk and Benedict, Boothby, Knoop, Mendel, Noyons, and de Barenne. A noteworthy tendency lay in the simplification of technique, and the applicability of the new methods to clinical practice. A summary was given by Mann (Rochester, Minn.) of his work on the dehepatised animal. Interest in the question of vitamins seems recently to have diminished, very few communications being made.

The study of digestion has now definitely shifted out of the hands of Pavlov's school to America, from whence the pupils of Carlsson, and particularly Ivy, brought communications dealing with the phases of gastric and pancreatic secretion.

Circulation was represented from America by Wiggers (Cleveland), who discussed the fractionate nature of ventricular contraction. The British school was represented by Anrep, who gave papers upon the central and reflex regulation of the coronary circulation (mainly in regard to the innervation of the coronary blood vessels), and upon the electrical measurement of coronary circulation during the single cardiac cycle. Heymans (Ghent) communicated the results obtained with his method of cerebral perfusion as applied to the study of the respiratory and cardioinhibitory centres. Frédéricq (Liège) summarised the results of his recent work upon chronaxie, especially in relation to the influence of the vagus and sympathetic cardiac nerves.

Prof. Loewi (Graz), in one of the most interesting papers of the congress, gave an account of the various factors affecting the rate of destruction of the chemical substance determining the inhibitory action of the vagus upon the heart. The work of this school would seem to bring us one step nearer to comprehension of the ultimate mechanism of peripheral inhibition.

An important contribution to the problem of hæmophilia was made by Howell (Baltimore), who brings evidence that the determining factor in this condition lies in an unusual stability of the blood platelets. In a second communication, Howell discussed the chemical nature of the anti-coagulant NO. 2970, VOL. I I 8$]$ 
substance heparin, which is so largely and successfully replacing hirudin in the experimental laboratories of the United States and Great Britain.

With regard to the chemistry of blood, Nicloux (Strasbourg), although unfortunately unable to be present in person, contributed a new spectroscopic method for the determination of small quantities of carbon monoxide in gas mixtures, applying his method to the determination of minimal quantities of it in blood. In a further paper this author presented a new determination of the oxygen content of methæmoglobin, fixing it at half the oxygen content of oxyhæmoglobin of the same blood.

In the present congress demonstrations played what might perhaps be called a secondary part. Many, such as those of Adrian, Kato, and Hill, were in demonstration of communications. Especially interesting in this group was a demonstration by Brinkman (Groningen) of his method of registering the attainment of $p \mathrm{H}$ equilibrium in $\mathrm{H}_{2} \mathrm{CO}_{3}$-bicarbonate buffer solutions. Barcroft gave a summary of his recent work on the spleen, supplemented by a demonstration. This seems, at last, to find some definite and important physiological function for an organ which has baffled physiological thought for centuries. Lim (Peking) gave a demonstration of a dog with transplanted stomach. Of especial interest also was a demonstration by $\mathrm{Y}$. Henderson (New Haven) of his method of measuring the circulation by inhalation of ethyl iodide. This seems to be the simplest and most tangible method up to the present, and most probably will find a great future application.

America, as in eleven successive congresses previously, sent a strong contingent of workers, and as was only as fair as it was unanimous, the twelfth congress accepted the invitation of the American Physiological Society that the thirteenth congress be held in America in r929.

It is, perhaps, of especial interest to mention also the good attendance from Russia, showing that the worst period in that country is approaching an end. Dr. Orbeli (Leningrad), who was present, did not, unfortunately, submit any summary of the results of his experiments upon the sympathetic innervation of voluntary muscle, a problem on which we know him to have been engaged for several years. Prof. I. P. Pavlov, the doyen of the congress, showed no sign of diminished activity in spite of his advancing years. There were no communications from his laboratory, although he informs us that a full description of his work on the cerebral cortex is being published in English towards the end of the present year.

The thanks and appreciation of all the members of the congress to their colleagues and hosts in Sweden was expressed by Profs. Gley, von Frey, and Starling at the final meeting of the congress at Upsala, and also previously and more lightly by the same representative speakers at the banquet given to the members of the congress by the City of Stockholm.

\section{The Geological Search for Oil.}

$\mathrm{O}^{\mathrm{x}}$ CE more the ubiquitous problem of the origin of petroleum is forced on our attention, this time as a practical matter rather than as a philosophical thesis. Dr. Murray Stuart writes a paper in the recent issue of the Journal of the Institution of Petroleum Technologists in which "working hypotheses ' in the geologist's search for oil form the main theme, the principal argument being that all exploration for petroleum is handicapped at the outset by the fact that little, if anything, is known concerning its origin. We appreciate the laws governing migration and accumulation of oil ; we contemplate favourable geologic structures, providing the strata involved are oil-bearing, which are located with remarkable precision; but unless the oil manifests itself by seepage or in some indirect manner, there is little to guide the search. To this extent, it may be noted, the geology of petroleum differs from the geology of, for example, metalliferous ore deposits.

One of the earliest and best known working hypotheses in oil-geology is that attributable to David White, whereby the degree of progressive devolatilisation (or metamorphism) of coal is interpreted as a measure of the chances of obtaining oil or gas in commercial quantity in associated deposits, the percentage of fixed carbon (pure coal basis) being the determining factor. White's law has found ample vindication in the West Virginia oil-fields, but it is not of universal application, as pointed out by Wade in a recent paper on "The Search for Oil in Australia"; the author, however, seeks to amend the law to the extent of excluding the idea of subsequent 'metamorphism' in favour of carbon ratio variation being interpretable in terms of normal processes of sedimentary deposition. He visualises his carbonaceous material as part of a sheet of sediment in which transition from conglomerate " . . . through sand and shale to oil-bearing shale,... through something equivalent to Torbanite into more or less pure carbonaceous material ..." is perceptible; carbon ratio variations are thus functions of original influences (mother-substance, environment, etc.), not of subsequent change in the course of geologic time. From this point of view is deduced the hypothesis that, assuming the carbon ratio of a fresh-water or estuarine coal seam to be favourable (i.e. 50 to 55 ), the seam will probably pass through torbanite into oil shale when traced in the direction from which the material composing the seam was initially derived. In the case of coals deposited under marine conditions, lateral variation into petroleum or into oil-shale (depending on the nature of the organic material incorporated in the sediment) is probable. A further hypothesis states that ". . . when formations containing abundant fossil-wood occur the underlying marine formations may contain liquid petroleum," and has been reasoned by the author in previously published papers.

The occurrence of oil in dolomitised limestones of lagoon formation furnishes the author with a contrasted, though in some respects parallel, line of argument; he examines this environment from a biochemical point of view, directing attention to the rôle of foraminifera and other protozoa, and also bacteria, in promoting essential mother-substance, whence he formulates the hypothesis that " all dolomitised limestones of lagoon formation are worthy of thorough investigation, provided that they prove, on microscopic examination, to be foraminiferal."

What we may term the "coal-to-conglomerate" hypothesis of the author raises problems at least as controversial as those of the origin of petroleum itself, though there is considerable novelty, if not practical import, in the views he puts forward. For the " many examples known in the world of coal seams and lignite seams passing laterally into either oil-shales or oil deposits " there are as many in which no coal-oil association is apparent. The tracing of a coal seam into an oil-shale seam in existing economic circumstances would be little reward to the geologist 